\title{
A percepção dos mineradores a respeito da sinalização na indústria carbonífera do sul de Santa Catarina
}

The perception of the miners regarding the signaling in the coal industry of the south of Santa Catarina

GUIMARÃES, Friedrich Junkes; Graduando; Faculdade Satc

fredjunkes@gmail.com

DENARDI, Davi Frederico do Amaral; Mestre; Faculdade Satc denardi.davi@gmail.com

\section{Resumo}

As minas subterrâneas são conhecidas pelos desafios relacionados à segurança e riscos à saúde dos trabalhadores. Apesar de ao longo dos últimos anos regulamentações e ações preventivas serem aplicadas faz-se necessário saber se o ambiente da mina ainda apresenta problemas relacionados à sinalização. Assim, o presente estudo buscou levantar a percepção dos mineradores em relação à sinalização a fim de identificar problemas. Para tanto 34 mineradores do sul de Santa Catarina foram responderam um questionário relacionado à problemática da ergonomia visual. Os resultados sugerem que o atual ambiente da mina de carvão não apresenta grandes problemas de comunicação visual.

Palavras Chave: mineração; sinalização.

\begin{abstract}
Underground mines are known for challenges related to safety and health risks to workers. Although over the last few years regulations and preventive actions have been applied it is necessary to know if the mine environment still presents problems related to signaling. Thus, the present study sought to raise the perception of the miners in relation to the signaling in order to identify problems. For this purpose, 34 miners from the south of Santa Catarina received a questionnaire related to the problem of visual ergonomics. The results suggest that the current coal mine environment does not present major visual communication problems.
\end{abstract}

Keywords: mining; signaling.

\section{Introdução}

A mineração tem sido explorada a tempos com extração de diversos minérios. No seu início essa exploração era praticada sem segurança, causando problemas de saúde e revolta por parte das famílias dos trabalhadores. Porém, com a evolução social e tecnológica melhorias nos sistemas operacionais das empresas proporcionaram relações pessoais mais 
agradáveis, equipamentos surgiram diminuindo o esforço e os danos à saúde dos trabalhadores e a produção começou a ser mais eficiente e segura.

A ergonomia foi um dos campos de estudo que contribuiu muito para esta evolução. Sendo uma área do conhecimento multidisciplinar os estudos ergonômicos procuram adaptações do meio para com o homem, sejam estas adaptações físicas, psicológicas ou sociais. Busca-se através de um olhar ergonômico o conforto, a eficiência e a segurança do ser humano diante de uma interação com um sistema.

Um dos aspectos que este artigo aborda dentro da ergonomia é o visual, com uma contribuição do design gráfico as informações visuais podem gerar reações mais rápidas, facilitando a compreensão do público a quem é comunicado.

\section{Mineração subterrânea: Atividades e riscos}

As atividades em ambientes de mineração subterrânea são caracterizadas como mecanizadas, semi-mecanizadas e manuais, ou seja, quando as tarefas são realizadas com equipamentos ou com ferramentas manuais sempre com a presença dos trabalhadores sob a terra. (MAIA, 1979).

Pode ser feita também uma divisão entre atividades estruturadas ou informais, onde as informais são identificadas pela falta de cumprimentos das determinações técnicas e legais diante da segurança e do ambiente de trabalho, colocando em risco os trabalhadores. Em contraponto, as estruturadas prezam a segurança e a saúde do trabalhador respeitando o meio ambiente e os recursos minerais. (MAIA,1979).

A mineração subterrânea é um trabalho muito antigo onde pode-se contrair doenças e causar lesões, e por isso devem ser feitas análises e avaliações mais aprofundadas sobre esses riscos a fim de minimizar ou até mesmo acabar com as chances de danos. (DONOGHUE, 2004).

Os trabalhos em mineração subterrânea operacionalmente estruturada, possuem um ciclo de operações básicas que, segundo Thomas (1979), Hartman e Mutmansky (2002) e Hustrulid (2001), envolvem de forma geral as etapas de perfuração da rocha, desmonte da rocha (com explosivos ou de forma mecânica), abatimento de choco (blocos de rochas semi soltos), carregamento e transporte do material desmontado, contenção e reforço do teto e das paredes da mina, equipagem da mina e frente desmontada.

Dentro deste ciclo existem dois momentos que oferecem maiores riscos, que são o abatimento de chocos e o transporte do material desmontado.

No abatimento de chocos, que consiste em derrubar as rochas semi soltas no teto e nas laterais das galerias em uma mina, o perigo está na possibilidade de uma rocha se soltar em um momento não esperado podendo resultar em acidentes fatais. No momento do transporte são carregadas as peças desmontadas na frente das minas para fora com caminhões e carregadeiras, Foster e Burton (2006), Eger et al. (2004) e Godwin et al. (2007) comentam sobre a postura e a visibilidade dos operadores das carregadeiras utilizadas nas minas subterrâneas tipo LHD, descrevendo sobre a dificuldade dos operadores de ver as pessoas, os objetos ou avaliar os perigos em torno da máquina, devido aos ângulos mortos e à reduzida linha de visão no ambiente subterrâneo

Durante este ciclo, existem ainda as atividades de engenharia e geologia, incluindo manutenção, drenagem e abastecimento, que acompanham o planejamento, $\mathrm{o}$ desenvolvimento e a operação da mina subterrânea.

Como as anomalias geológicas são imprevisíveis o trabalho em uma mina requer as 
respostas a tais mudanças repentinas, no qual é necessário experiência, conhecimento e habilidade de tomar decisões rápidas e seguras, sendo estes aspectos objetos de estudo da ergonomia cognitiva, além de esforço físico e posturas inadequadas dos trabalhadores que podem ser abordados pela ergonomia física.

Almeida (2004), Amalberti (2000) e Iida (2005), ambiente da mineração pode apresentar riscos à saúde do trabalhador, sendo que parte deles podem ser minimizados por meio de elementos de ergonomia cognitiva, sobretudo a comunicação visual, devidamente adaptados ao ambiente úmido e escuro da mina.

\section{A relação da ergonomia cognitiva com a segurança do trabalho}

A ergonomia cognitiva se refere à interação do homem com os elementos físicos e sociais a sua volta, analisando as atividades mentais realizadas para relação com máquinas e artefatos. (DE ARRUDA, 2011).

Ela é um campo de estudo dos processos mentais que começam antes e continuam presentes durante a operação de um sistema, criando um plano que possibilita prever as atividades a serem efetuadas, e contribuindo para resolver e eliminar rapidamente qualquer dificuldade durante a atividade planejada, tomando decisões rápidas (DE ARRUDA, 2011).

Estudos cognitivos ainda revelam que a memória, a percepção, coordenações motoras e interações operacionais e sociais tem relação direta com as tomadas de decisões, estresse diante do aprendizado e experiências com cada sistema e ambiente. (DE ARRUDA, 2011).

\section{Ergonomia visual e Sinalização}

O projeto de sinalização trata de tornar a localização de lugares, assim como a auto localização, mais fácil, rápida e ágil, por meio da utilização de elementos que tornam o deslocamento mais intuitivo, passando maior segurança as pessoas que o utilizam. Scherer (2014, pg. 10) cita como conceitos de sinalização: "o planejamento, projeto e especificação de elementos gráficos no ambiente construído ou natural, com o intuito de identificar, informar, direcionar e orientar".

Nessa área são utilizadas várias formas para orientar, mas há duas que se destacam por sua funcionalidade, que são: a sinalética e os sistemas de wayfinding. Segundo Costa (2011, p. 98), "sinalética é uma parte da nova ciência da comunicação ambiental, que tem por objetivo tornar inteligíveis os espaços de ação dos indivíduos, sobretudo no mundo dos serviços, onde cada caso e espaço é diferente" Passar a informação de forma rápida e precisa, se adequando ao espaço em que está, até mesmo reforçando a identidade do local.

Um dos princípios é o da "economia generalizada: máxima informação com o mínimo de elementos e com o mínimo de esforço do receptor para sua identificação e compreensão." Scherer (2014, pg. 7)

$\mathrm{Na}$ construção de um projeto, existem elementos que auxiliam na sinalização, como placas, tipografia, pictogramas e mapas. Para isso, Pezzin (2013) cita que, as formas, cores e tipografia devem seguir um padrão que seja distinguível de outros padrões. Sendo assim, a seguir serão explanados sobre dois importantes elementos que compunham um sistema de sinalização.

\section{Tipografia}

Quanto a escolha do tipo ou da família tipográfica a ser usada, Scherer et al (2012, p. 4) 
relatam que "deve-se levar em conta os aspectos conceituais como a adequação ao ambiente e a mensagem a ser transmitida, assim como o aspecto técnico e a legibilidade". A tipografia ideal para sinalização, fica em harmonia com o local onde está, transmitindo a identidade do ambiente.

Ao usarmos a combinação tradicional de caixa alta e baixa (maiúsculas e minúsculas), criando um desenho mais iconográfico, facilitamos a leitura de um texto, isso acontece porque lemos palavra por palavra e não letra por letra. (Scherer et al, 2012) No momento que lemos a palavra, a silhueta da mesma influencia na sua leitura.

Para Pereira e Gonçalves (2010), é a “qualidade tipográfica de um texto que determina a sua facilidade de leitura, que também pode ser considerada um modo de percepção ligada à recepção de uma informação e o seu reconhecimento, pela comparação armazenada na memória do indivíduo."

\section{Cores}

Para Scherer e Uriartt (2007, p. 9) "cores estimulam os usuários a mover-se dentro do espaço de uma forma mais segura, pois a repetição e o ritmo visual criado a partir do uso delas auxilia o usuário a seguir a informação. As cores ajudam o usuário a lembrar de informações."

Scherer e Uriartt (2007, p. 6) descrevem que, "além dos aspectos funcionais, o uso da cor em sinalização pode ajudar a criar a identidade tanto de uma marca quanto do sistema em si" o autor também cita que a cor auxilia na diferenciação e identificação de setores, "constata-se assim que parte do significado da mensagem é transmitida antes do elemento ser lido. (SCHERER E URIARTT, 2007, p. 7).

Dado o exposto é possível supor que alguns os riscos de uma mina de carvão podem ser minimizados por meio da sinalização. E para tanto faz se necessário em um primeiro momento identificar as percepções dos próprios mineiros a respeito do tema.

\section{Procedimentos metodológicos}

O presente estudo se caracteriza como uma pesquisa básica, qualitativa e exploratória, tendo como principal procedimento técnico um levantamento junto a 34 trabalhadores da indústria carbonífera no sul de Santa Catarina.

Todos os participantes desenvolvem atividades técnicas no ambiente do subsolo conforme descrito a seguir: Eletricista (7), Mecânico (2), Encarregado (2), Servente (2), Operador de britador (2), Mecânico beneficiamento (1), Auxiliar Superfície (1), Furador (1), Mecânico de manutenção (1), Bombeiro (1), Engenheiro de segurança no trabalho (1), Eletricista automotivo (1), Operário (1), Mecânico de finos (1), Operador (1), Gigueiro (1), Operador de máquinas (1), Mecânico de manutenção hidráulico (1), Técnico de segurança do trabalho (1), Supervisor de beneficiamento (1), Operador de fresa(1), Auxiliar mecânico (1), Soldador (1).

Todos os participantes eram homens com idade média de 32 anos $(\mathrm{DP}=12,2)$ e tempo médio de experiência de 8,1 anos (DP=9).

O principal instrumento de coleta de dados foi um formulário composto por 7 questões com respostas na forma de uma escala Lickert de 5 opções e um espaço para respostas descritivas. O formulário foi distribuído por e-mail (contabilizando 8 respostas) e impresso (contabilizando 26 respostas).

A escolha do instrumento de coleta de dados se justifica dada a dificuldade de acesso ao 6o GAMPI Plural, 2017, Joinville, SC. 
ambiente da mina e de recrutamento. Em um primeiro momento os pesquisadores solicitaram uma visita presencial às minas, porém, por motivos de segurança ela não foi possível. Uma segunda tentativa foi a entrevista presencial com os mineradores, sendo identificados 31 mineradores junto ao curso de Engenharia de Minas da Faculdade Satc em Criciúma/SC. Porém, apenas dois deles concordaram em participar da pesquisa.

Dado o exposto a coleta de dados foi alterada para o formulário, já que este é mais facilmente distribuído e evita transtornos de agendamento e mesmo de constrangimento.

A amostragem se deu por meio da técnica snowball (VINUTO, 2016) sendo iniciada pelos dois mineiros que foram entrevistados inicialmente, a partir deles os formulários foram encaminhados a colegas de estudo e de trabalho. Juntamente com o formulário foi encaminhado o Termo de Consentimento Livre e Esclarecido.

Incialmente o formulário foi formatado para identificar o perfil geral do colaborador, solicitando a sua idade, cargo e tempo de experiência na mineração.

Em seguida eram apresentadas as seguintes perguntas.

\section{Pergunta 1 - Como é a identificação dos funcionários? Por que?}

Essa questão tem como objetivo identificar como os trabalhadores se reconhecem dentro da mina, uma vez que o ambiente de mineração pode apresentar uma iluminação deficiente, conforme sugerem Donoghue (2004), Almeida (2004), Amalberti (2000) e Iida (2005).

Pergunta 2 - Como é a sinalização da mina (Placas, guias, posição, cor)? Por que?

Ainda segundo Donoghue (2004), Almeida (2004), Amalberti (2000) e Iida (2005), o projeto de sinalização é uma das formas de mitigar os problemas de identificação de locais e de comunicação.

\section{Pergunta 3 - Como é a iluminação? Por que?}

A mina subterrânea pode ser classificada como um lugar úmido, confinado e escuro (DONOGHUE, 2004), assim é preciso avaliar o grau de problemas de iluminação presentes nesse ambiente atualmente. Ainda é preciso salientar que a iluminação tem efeito direto na percepção de informações (DE ARRUDA, 2011).

\section{Pergunta 4 - Como é a locomoção e a identificação dos diferentes lugares dentro da mina? Por que?}

As atividades de mineração possuem um ciclo de operações básicas entre eles a locomoção de pessoal e transporte de materiais (THOMAS, 1979; HARTMAN E MUTMANSKY, 2002; HUSTRULID, 2001). Nesse sentido, a sinalização pode contribuir para a eficiência e segurança dessa atividade. Assim, faz-se necessário conhecer a percepção dos trabalhadores a respeito desse processo de locomoção.

\section{Pergunta 5 - Quais são as atividades diárias? Como essas atividades são informadas a você? que? \\ Pergunta 6 - Como é o acompanhamento dos supervisores nas tarefas diárias? Por}

As questões cinco e seis tratam da dinâmica de comunicação de informações, e da mesma maneira que conhecendo a maneira de locomoção dentro da mina e qual o seu trajeto, 
ao conhecer as atividades realmente realizadas é possível pensar em medidas preventivas, avaliar se as informações visuais estão auxiliando corretamente as tarefas exigidas, como essas tarefas estão propostas aos trabalhadores.

\section{Pergunta 7- Alguma sugestão de melhorias de comunicação visual?}

Os trabalhadores são os que convivem com o ambiente e que conhecem seus perigos, riscos e problemas que encontram na sua jornada de trabalho, e neste momento é aberto um espaço para que eles possam identificar esses pontos e contribuam para melhorias.

\section{Resultados}

A seguir serão descritas e discutidas as respostas dos colaboradores.

Gráfico 1 - Como é a identificação dos funcionários.

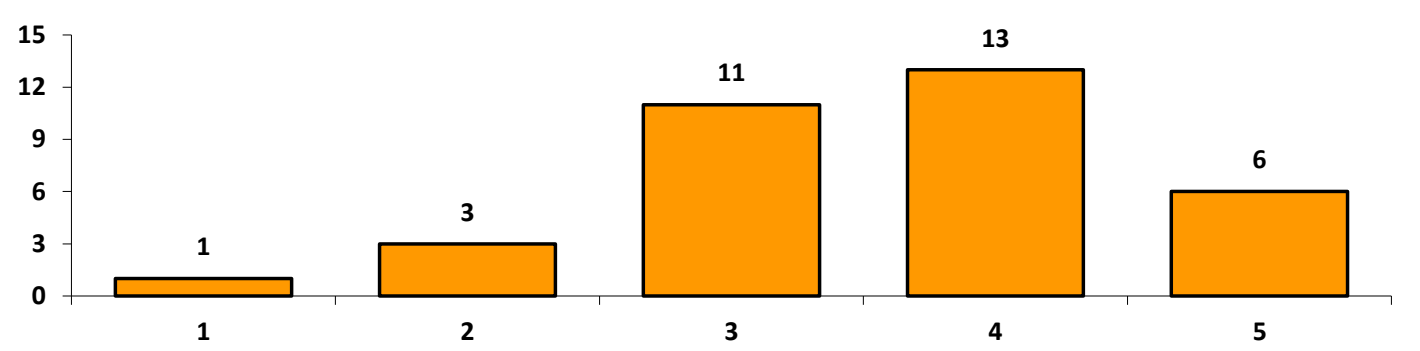

Em relação à identificação dos funcionários da mina (tema da pergunta 1) nota-se que tiveram uma boa avaliação. Os trabalhadores usam uniformes, capacetes, porém não existe um consenso em relação à diferenciações entre cargos, funções, em alguns ambientes os mineradores relataram que também não possuem identificação individual.

Os resultados para a primeira questão (Gráfico 1) indicam pouco consenso em relação à identificação dos colaboradores, com uma leve aprovação do sistema de identificação. Segundo as respostas qualitativas, colaboradores, brigadistas e chefes de setor são identificados com roupas e capacetes de cores diferentes. Sendo que um participante afirmou que não há qualquer identificação visual.

Gráfico 2 - Como é a sinalização da mina (Placas, guias, posição, cor).

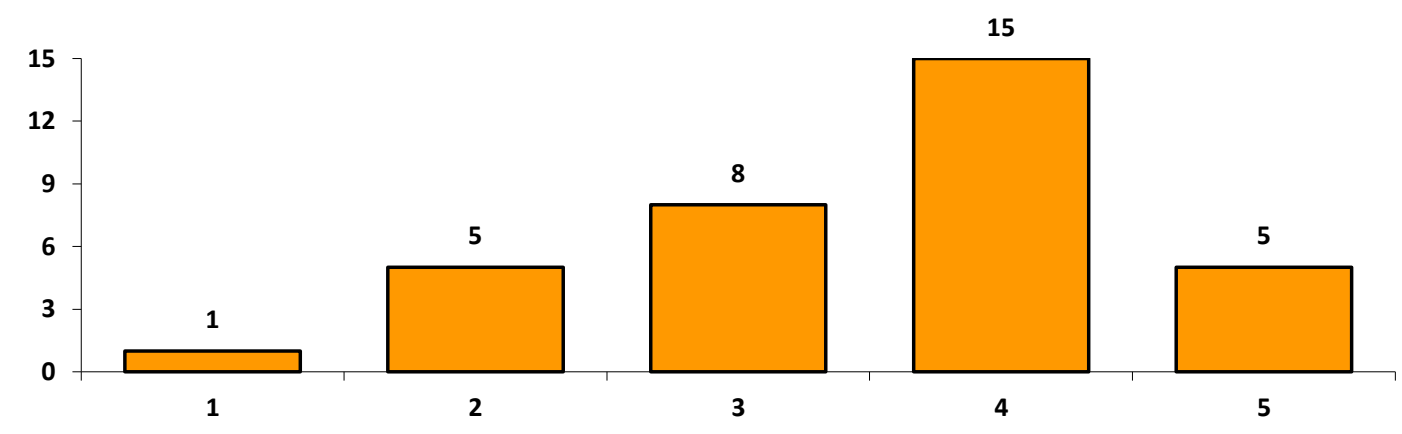

Também em relação à sinalização (Gráfico 2), percebe-se certo consenso que os atuais sistemas de sinalização são adequados ao desenvolvimento das atividades diárias. Nas 


\section{GAMPI}

respostas qualitativas um dos mineradores respondeu que para usuários iniciantes a sinalização pode se tornar confusa dada a complexidade das estruturas da mina, contudo com pouco tempo de experiência ela se torna satisfatória. Dois usuários também indicaram a preocupação com o sistema de sinalização em caso de um sinistro. Na opinião desses dois últimos participantes a sinalização atual pode trazer riscos em caso de sinistro.

Gráfico 3 - Como é a iluminação.

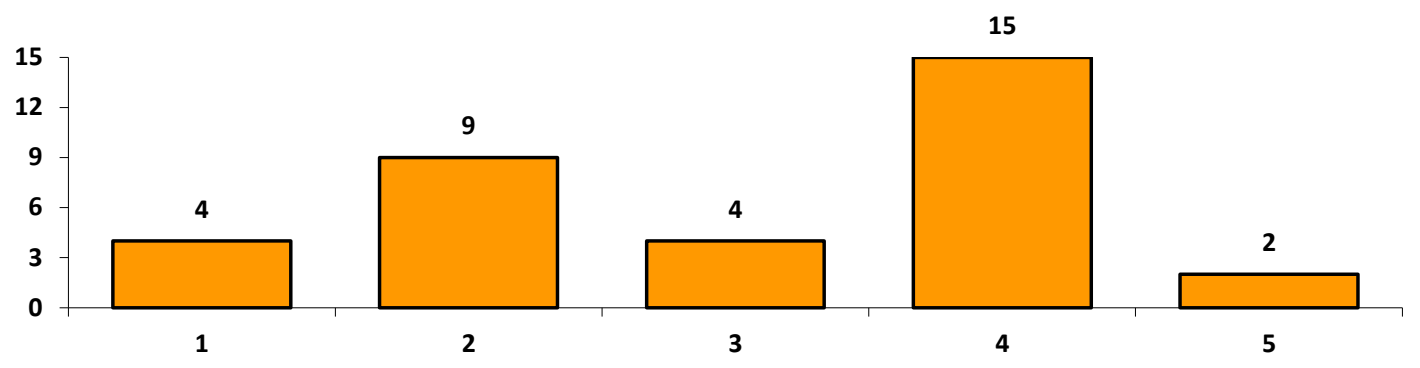

A iluminação das minas foi o tema da terceira questão, mas nesse caso não se observa um consenso explícito conforme pode-se observar na Gráfico 3. Em relação às causas das avaliações, dois participantes citaram que existe boa iluminação nos lugares de uso comum, trajeto, mesa de café e nos demais os funcionários possuem lanternas nos capacetes, por outro lado, um dos comentários afirma que faltam investimentos em iluminação, especialmente pelas especificidades do ambiente da mina.

Gráfico 4 - Como é a locomoção e a identificação dos diferentes lugares dentro da mina.

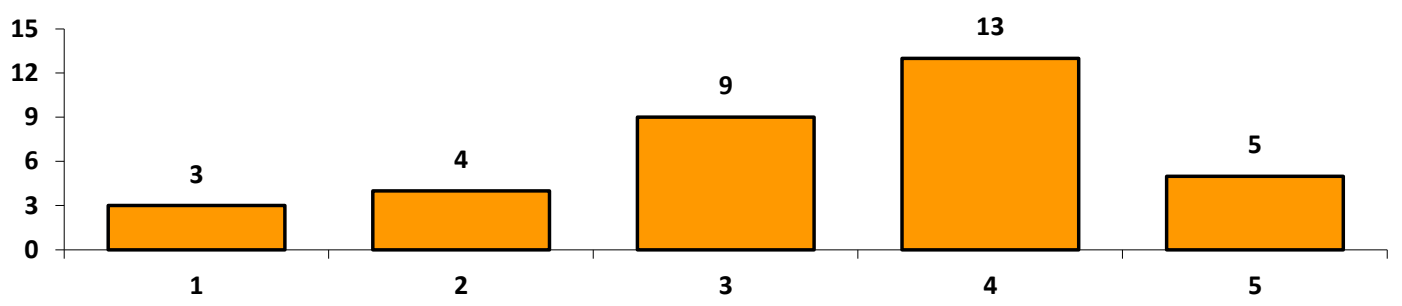

A quarta pergunta (Gráfico 4) procura identificar a percepção dos mineradores a respeito das atividades de transporte que também teve leve aprovação dos mineradores. Dentro das respostas qualitativas um minerador afirma que assim como a sinalização, em um primeiro momento o processo de locomoção é confuso, mas que com o tempo ele se torna eficaz. Outro minerador afirmou que o terreno acidentado dificulta a locomoção.

Gráfico 5 - Quais são as atividades diárias? Como essas atividades são informadas a você? 


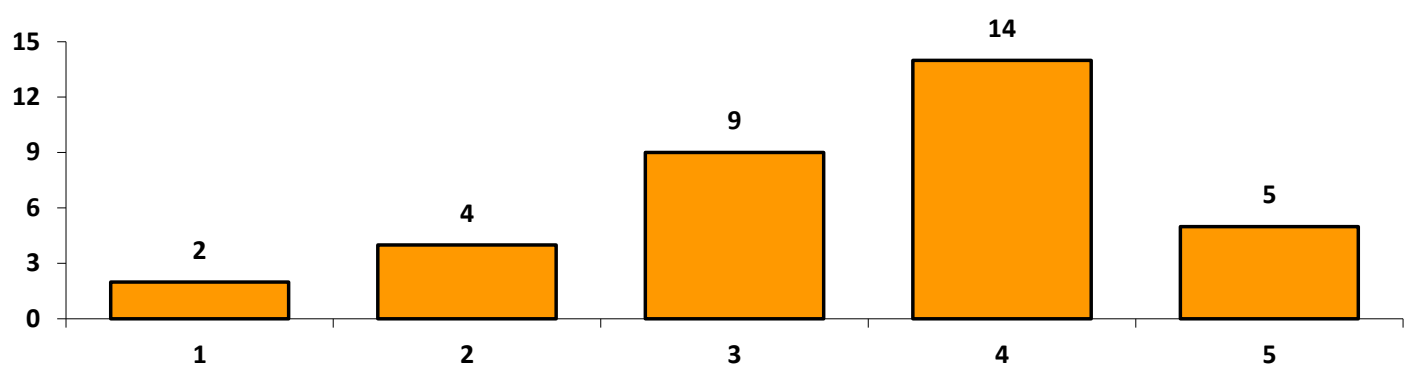

Em forma descritiva a quinta pergunta (Gráfico 5) buscava compreender como os funcionários eram informados e quais eram as suas atividades que eles exerciam na mina. Segundo os relatos dos participantes as atividades variam dependendo das necessidades do dia e eram comunicadas por livro ponto, ordem se serviço, memorandos ou através dos encarregados diante dos planos feitos. Outra característica citada foi que as atividades eram sempre corretivas, nunca preventivas.

\section{Gráfico 6 - Acompanhamento}

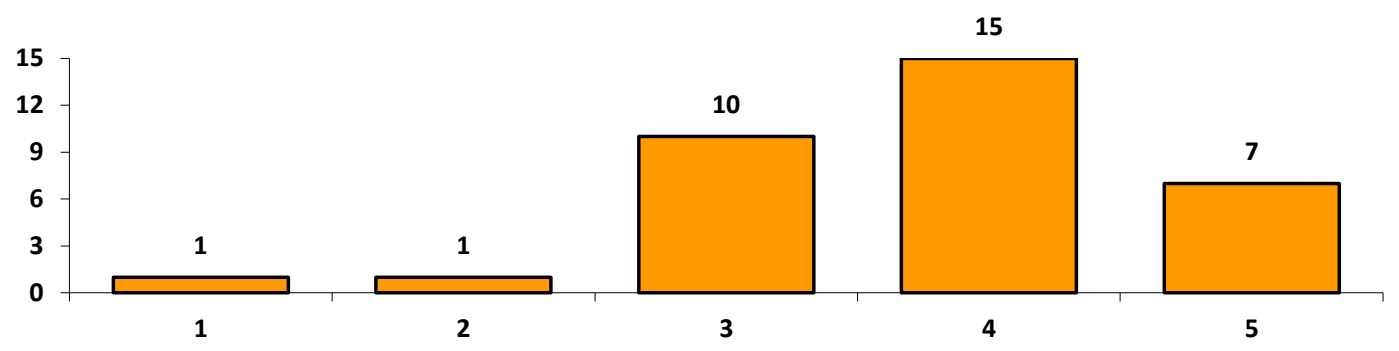

A sexta pergunta (Gráfico 6) se dirigiu ao acompanhamento dos supervisores, onde se mostrou bem presente. Nas justificativas desta avaliação não foi tão positiva, relatando que a cobrança e a presença dos supervisores em certos momentos geram uma certa pressão sobre os trabalhadores, sendo este acompanhamento visto por um ponto negativo no relacionamento entre os funcionários.

A última oportunidade de participação da entrevista buscava sugestões diretas dos trabalhadores, procurando saber o que eles tinham como ponto de vista do ambiente de trabalho. Foram obtidas apenas três contribuições, na qual sugeriram uma melhoria na limpeza dos ambientes, renovas as pinturas da estrutura e desenvolvimento de um plano de ação e comunicação em caso de sinistro.

\section{Conclusão}

O ambiente da mineração apresenta grandes desafios para a sinalização porque é por natureza um ambiente com altos riscos, dada a sua exploração ser subterrânea, com baixa iluminação e grandes ruídos tanto visuais quanto auditivos.

Assim, o objetivo deste estudo era o de identificar possíveis pontos críticos de atuação sob o ponto de vista do design, sobretudo em relação à sinalização e comunicação.

Os resultados sugerem que atualmente o ambiente da mina subterrânea possui poucos pontos explicitamente críticos para a sinalização. No caso dos dados coletados, estes pontos se dão em relação à iluminação da mina, já que no caso da mineração carbonífera paredes e teto são escuros e na frente de trabalho (local onde são feitas as primeiras perfurações) a falta 
de referências visuais pode gerar riscos.

Além disso, pode-se considerar que o planejamento de rotas e elementos de comunicação em caso de um sinistro pode ser considerado relevante como elemento de sinalização.

Também é preciso salientar que os dados aqui apresentados são resultado de um formulário e apenas refletem a percepção dos mineradores, assim, outros riscos menos explícitos ou mesmo ignorados involuntariamente pelos colaboradores podem existir na mina, o que sugere a necessidade de outros procedimentos de coleta de dados, como a observação sistemática desse ambiente.

Assim, sugere-se para trabalhos futuros a observação do ambiente. Também se sugere o planejamento de ações ou produtos que contribuam para a iluminação da frente de trabalho e o estudo de procedimentos para o caso de sinistros.

\section{BIBLIOGRAFIA}

IIDA, I.; Ergonomia, projeto e produção; (2005), São Paulo.

FALZON, P. Ergonomia. São Paulo: Blucher, 2007. xxi, 640 p. ISBN 9788521204121.

CHAMMA, N, PASTORELO, P. A justa medida da sinalização. InfoDesign Revista Brasileira de Design da Informação 5 - 2 [2008], 72 - 74 ISSN 1808-5377

COSTA, J. Design para os olhos: Marca, cor, identidade, sinalética. 1.ed. Lisboa: Dinalivro, 2011.

PEREIRA, C, GONÇALVES, B. A configuração da informação do sistema de sinalização do Terminal Integrado do Centro de Florianópolis: Anais do $9^{\circ}$ Congresso Brasileiro de Pesquisa e Desenvolvimento em Design, 2010.

PEZZIN, O. C. Design de sinalização do Metrô de São Paulo: estudo de caso de sua manutenção. São Paulo, 2013.

SCHERER, F. V. Design Gráfico Ambiental: Revisão e definição de conceitos. Gramado, $201411^{\circ}$ P\&amp;D.

SCHERER, F. V.; CARDOSO, E.; FETTER, L. C. Levantamento e Caracterização de Famílias Tipográficas para uso em Sistemas de Sinalização: PeD Design, 2012.

SCHERER, F. V.; PEREIRA. S. T. O uso da cor em sistemas de sinalização. $12^{\circ}$ Congresso internacional de ergonomia e usabilidade de interfaces Humano-Tecnologia: Produto Informações, ambiente construído e transporte, (2012).

DE ARRUDA, A. F. V.; Aplicação dos princípios ergonômicos nos sistemas de gestão de segurança e saúde do trabalho: Uma Proposta de Modelo Conceitual na Mineração Subterrânea. 2011. 216 f. Tese (Pós-Graduação em Engenharia de Produção) Programa de pós-graduação em engenharia de produção, UFSC, Florianópolis. 2011. 
HELEODORO, A.; Avaliação de riscos à saúde e segurança do trabalho em uma unidade de beneficiamento de carvão: estudo de caso. UNESC, Criciúma, 2011.

\section{Agradecimentos}

O presente estudo foi financiado pela Fundação de Apoio à Pesquisa Científica e Tecnológica do Estado de Santa Catarina (FAPESC). 